Genetic engineering

\section{Hepatitis vaccine wins approval}

Washington

THE US Food and Drug Administration last week approved for the first time the sale of a human vaccine made by recombinant DNA techniques. The vaccine, for hepatitis $B$, is to be manufactured by Merck, Sharp and Dohme of West Point, Pennsylvania, under the name Recombivax $\mathrm{HB}$, and was developed in collaboration with Chiron Corporation of Emeryville, California

Recombivax has a potential world market of hundreds of millions of doses for, unlike existing hepatitis-B vaccines, production is not limited by the need for plasma from infected patients. But at $\$ 100$ for the course of three injections, the vaccine costs about the same as conventional plasma-derived vaccines and is far too expensive for mass immunization programmes in countries where the disease is most common.

In East Asia and tropical Africa, more than 10 per cent of the population are chronic carriers, and active hepatitis and related cirrhosis are major causes of mortality. Worldwide there are about 300,000 liver cancer deaths per year, most of them thought to result from hepatitis- $B$ infection. In the United States there are 200,000 new cases of hepatitis each year. Those most at risk are offspring of infected mothers, health-care workers, intravenous drug users and male homosexuals.

Although a plasma-derived vaccine, also sold by Merck, has been available in the United States since 1981 only $3-30$ per cent of high risk groups have been vaccinated, partly because of fears that the vaccine might transmit acquired immune deficiency syndrome (AIDS). Although Merck says these fears are groundless the company hopes that the recombinant vaccine, which is produced in yeast cells, will prove more acceptable to members of high-risk groups.

Recombivax is made intracellularly in yeast cells that express the hepatitis-B surface antigen. Since early successes were reported in Nature $\mathbf{( 2 9 8 , 3 4 7 ; ~ 1 9 8 2 ) , ~}$ a more complex expression system has been developed, and improvements in expression and scale-up work done by Merck. Patents governing the process are held by the University of California, by Chiron and by the University of Washington. But there is a continuing dispute over some patent rights to the viral genome with Pierre Tiollais' group at Institut Pasteur in Paris, which was the first to obtain a complete viral sequence. The US Patent Office is likely to declare an "interference procedure" to consider the French claims. In the short term, the factor that will limit use of the recombinant product is price. Dr Joseph Melnick of Baylor Col- lege of Medicine estimates that the price of a treatment would have to come down to around $\$ 1$ to be widely used in mass immunization campaigns in the poorest countries, but is optimistic that the potentially unlimited supply of new vaccine will lead to its widespread use.

Dr William McAleer of Merck is also optimistic, believing that the recombinant vaccine made in yeast will in the long term become cheaper than the existing plasmaderived product. McAleer argues that constructing a suitable high-yielding clone has been the most expensive part of development; extraction and purification procedures are inherently cheaper for yeast-derived than for plasma-derived vaccines, because inactivation steps and innocuity testing are less elaborate.

The hepatitis- $\mathrm{B}$ antigen particles in
EACH year seems to deepen the despair of Britain's Advisory Board for the Research Councils (ABRC). In its annual claim for research funds, now under consideration by the Secretary of State for Education and Science, it finds need to reiterate, in bold type, that scientific research is relevant to "national needs". A series of increases in science spending over the next three years is called for.

The argument the report seems repeatedly to try to drive into the minister's mind is that the new technologies, principally

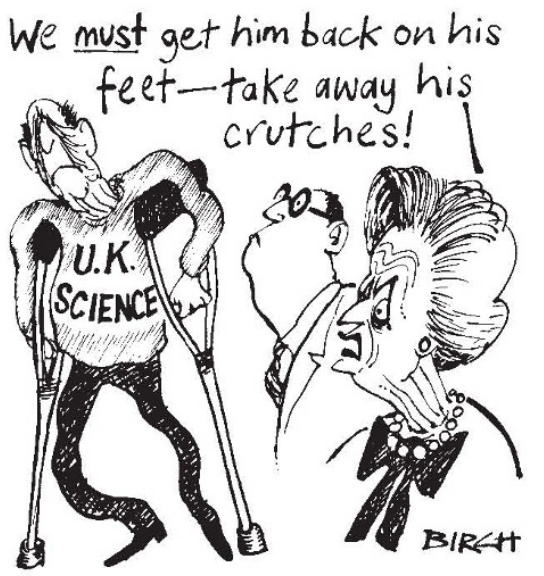

biotechnology and information technology, that the government hopes will revitalize the economy, are science-based and crucially dependent on advances in basic research. Demands on the science base, particularly from industry, are thus increasing while the volume of scientific research performed is falling because funds are not available. Evidence of the failure to keep up with other countries in investment can be seen in the brain drain
Recombivax are not identical to those from infected humans because they do not include polypeptides coded by the "pre-S" regions of the viral coat gene. In addition. lipid membrane in the particles is from yeast rather than human cells. Nevertheless, about 95 per cent of volunteers immunized in trials developed a strong antibody response and are presumed to be protected. But Chiron has already produced an experimental vaccine that does include pre-S polypeptides and it is hoped that it will provoke immunity in those who do not respond to the Recombivax HB.

Recombivax is Chiron's first therapeutic product to gain marketing approval and the company expects it to earn at least $\$ 100$ million a year. The only competitor is sold in Singapore by Smith Kline-RIT, a subsidiary of SmithKline Beckman based in Belgium. But Institut Pasteur in Paris and Genentech in the United States are likely to enter the market and then prices may fall.

Tim Beardsley

\title{
Research board pleads for more
}

of scientists from the United Kingdom and in a study from the Science Policy Research Unit that shows the per capita expenditure on science in to be the lowest in the industrialized world.

The report protests that everything that can be done to make better use of available money has been done. Dozens of research units have been closed, and more than 3,000 jobs lost to try to give better value for money.

But very little scope remains. If, as the report speculates, it is the government's intention to have a much smaller science base in Britain, there is not even enough money for an orderly transition.

By 1990 , the volume of research supported will be some 10 per cent less than at the beginning of the $1980 \mathrm{~s}$, despite the value of the science budget having been maintained. The trouble is that the costs of scientific equipment and materials rise much more rapidly than does inflation and this needs to be reflected in the budget.

To end the erosion of research the board asks for an increase over present figures (some $£ 614$ million in $1986-87$ ) of $£ 35$ million in 1987--88, £50 million in $1988-89$ and $£ 60$ million in $1989-90$. In addition, the Science and Engineering Research Council needs an immediate $£ 9$ million to compensate for recent rises in the cost of its subscriptions to international laboratories.

The signs are that the government will be hard to persuade. A white paper (policy document) released last week rejected recommendations from a select committee that the science budget be increased annually by at least three per cent above inflation.
Alun Anderson 